\title{
Credentialing of Hospitalists in Ultrasound-Guided Bedside Procedures: A Position Statement of the Society of Hospital Medicine
}

\author{
Brian P. Lucas, MD, MS $1,2 *$, David M. Tierney, MD³, Trevor P. Jensen, MD, MS', Ria Dancel, MD5, \\ Joel Cho, MD', Mahmoud El-Barbary, MD, PhD, MSc ${ }^{7,8}$, Ricardo Franco-Sadud, MD', \\ SHM Point-of-Care-Ultrasound Task Force**, Nilam J. Soni, MD, MS 10,11
}

\begin{abstract}
${ }^{1}$ Medicine Service, White River Junction VA Medical Center, White River Junction, Vermont; ${ }^{2}$ Geisel School of Medicine at Dartmouth College, Hanover, New Hampshire; ${ }^{3}$ Abbott Northwestern Hospital, Department of Medical Education, Minneapolis, Minnesota; ${ }^{4}$ Division of Hospital Medicine, Department of Medicine, University of California San Francisco, San Francisco, California; ${ }^{5}$ Division of Hospital Medicine, Department of Medicine, University of North Carolina, Chapel Hill, North Carolina; ${ }^{\circ}$ Division of Hospital Medicine, Kaiser Permanente San Francisco Medical Center, San Francisco, California; ${ }^{7}$ King Saud Bin Abdulaziz University for Health Sciences, Riyadh, Saudi Arabia; ${ }^{8}$ Department of Clinical Epidemiology and Biostatistics, McMaster University, Hamilton, Ontario, Canada; ' Division of General Internal Medicine, Medical College of Wisconsin, Milwaukee, Wisconsin; ${ }^{10}$ Division of General \& Hospital Medicine, The University of Texas School of Medicine at San Antonio, San Antonio, Texas; ${ }^{11}$ Section of Hospital Medicine, South Texas Veterans Health Care System, San Antonio, Texas.
\end{abstract}

Ultrasound guidance is used increasingly to perform the following 6 bedside procedures that are core competencies of hospitalists: abdominal paracentesis, arterial catheter placement, arthrocentesis, central venous catheter placement, lumbar puncture, and thoracentesis. Yet most hospitalists have not been certified to perform these procedures, whether using ultrasound guidance or not, by specialty boards or other institutions extramural to their own hospitals. Instead, hospital privileging committees often ask hospitalist group leaders to make ad hoc intramural certification assessments as part of credentialing. Given variation in training and experience, such assessments are not straightforward "sign offs." We thus convened a panel of experts to conduct a systematic review to provide recommendations for credentialing hospitalist physicians in ultrasound guidance of these 6 bedside procedures. Pathways for initial and ongoing credentialing are proposed. A guiding principle of both is that certification assessments for basic competence are best made through direct observation of performance on actual patients. Journal of Hospital Medicine 2018;13:117-125. Published online first January 17, 2018. (@ 2018 Society of Hospital Medicine

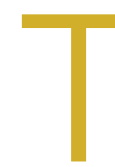

he American Board of Internal Medicine (ABIM) changed its certification policy for bedside procedures over a decade ago. ${ }^{1}$ Acquiring manual competence in abdominal paracentesis, arterial catheter placement, arthrocentesis, central venous catheter placement, lumbar puncture, and thoracentesis is no longer an expectation of residency training. ABIM diplomates should "know" these procedures but not necessarily "do" them. Hospitalists, most of whom are themselves ABIM diplomates, are still, however, expected to do them as core competencies, ${ }^{2}$ perhaps because hospitalists are often available off-hours, when roughly half of bedside procedures are performed. ${ }^{3}$

\footnotetext{
*Address for correspondence and reprint requests: Brian P. Lucas, MD, MS 215 N Main Street, White River Junction, VT; Telephone: 802-295-9363 extension 4314; Fax: 802-296-6325; E-mail: brian.p.lucas@dartmouth.edu
}

${ }^{\star *}$ A complete list of the Society of Hospital Medicine Point-of-Care Ultrasound Task Force members appears at the end of this article.

Additional Supporting Information may be found in the online version of this article.

Received: July 21, 2017; Revised: October 12, 2017; Accepted: October 19, 2017

2018 Society of Hospital Medicine DOI 10.12788/jhm.2917
Hospitalists increasingly perform bedside procedures with ultrasound guidance. ${ }^{4}$ Yet training in ultrasound guidance is significantly varied as well, ${ }^{5}$ simply because point-of-care ultrasound (POCUS) has only recently become widespread. ${ }^{6}$ And though some skills are transferrable from landmark-guided to ultrasound -guided procedures, many are not. ${ }^{7-10}$ Furthermore, ultrasound guidance is often not explicitly delineated on the privileging forms used by hospitals, ${ }^{11}$ even where ultrasound guidance has become standard. ${ }^{12}$

Given the variability in training for both ultrasound- and landmark-guided procedures, and given the lack of a universal standard for certification, local hospitals often ask their respective hospitalist group leaders to certify hospitalists' basic competence as part of credentialing (see the Table for definitions). How hospitalist group leaders should certify competence, however, is not clear. The importance of this gap has recently increased, as hospitalists continue to perform procedures despite not having clear answers to questions about basic competence. ${ }^{13-15}$

Therefore, the Society of Hospital Medicine (SHM) Education Committee convened a group of experts and conducted a systematic literature review in order to provide recommendations for credentialing hospitalist physicians in ultrasound-guided bedside procedures. These recommendations do not include 
training recommendations, aside from recommendations about remedial training for hospitalists who do not pass certification. Training is a means to competence but does not guarantee it. We believe that training recommendations ought to be considered separately.

\section{METHODS}

\section{Working Group Formation}

In January 2015, the SHM Board of Directors asked the SHM Education Committee to convene the POCUS Task Force. The purpose of the task force was to develop recommendations on ultrasound guidance for bedside procedures. The SHM Education Committee appointed 3 chairs of the task force: 1 senior member of the SHM Education Committee and 2 POCUS experts. The chairs assembled a task force of 31 members that included 5 working groups, a multispecialty peer review group, and a guideline methodologist (supplemental Appendix 1). Invitation was based on members' past contributions to SHM POCUS-related activities, up-front commitment, and declared conflicts of interest. Working group members self-identified as "hospitalists," whereas peer reviewers were nonhospitalists but nationally recognized POCUS physician-leaders specializing in emergency medicine, cardiology, critical care medicine, and anesthesiology. Task force membership was vetted by a chair of the SHM POCUS Task Force and the Director of Education before work began. This position statement was authored by the Credentialing Working Group together with the chairs of the other 4 working groups and a guideline methodologist.

\section{Disclosures}

Signed disclosure statements of all task force members were reviewed prior to inclusion on the task force (supplemental Appendix 2); no members received honoraria for participation. Industry representatives did not contribute to the development of the guidelines nor to any conference calls or meetings.

\section{Literature Search Strategy}

A literature search was conducted by a biomedical librarian. Records from 1979 to January of 2017 were searched in Medline, Embase, CINAHL, Cochrane, and Google Scholar (supplemental Appendix 3). Search limiters were English language and adults. Articles were manually screened to exclude nonhuman or endoscopic ultrasound applications. Final article selection was based on working group consensus.

\section{Draft Pathways}

The Credentialing Working Group drafted initial and ongoing certification pathways (Figure 1 and Figure 2). The other 4 working groups from the task force were surveyed about the elements and overall appropriateness of these draft pathways. This survey and its results have already been published.12 The Credentialing Working Group then revised

TABLE. Definitions

\begin{tabular}{ll} 
Term & Definition \\
\hline Active surveillance & $\begin{array}{l}\text { Systematic, ongoing monitoring for timely information about all attempted ultrasound-guided procedures within an institution, whether successfully completed or not. } \\
\text { Unlike passive surveillance, active surveillance does not rely solely on self-reported information about a hospitalist's performance. }\end{array}$ \\
\hline Basic competence & $\begin{array}{l}\text { Having demonstrable abilities, }{ }^{105} \text { both cognitive and manual, }{ }^{1} \text { that allow for successful and safe outcomes without expert supervision. } .^{106} \text { Basic cognitive competence } \\
\text { in an ultrasound-guided procedure is demonstrating knowledge of all facets of that procedure. Basic manual competence, on the other hand, is demonstrating safe } \\
\text { and dexterous performance of that procedure on a typical patient in the usual practice environment with available equipment; this includes having the judgment to } \\
\text { consult an appropriately skilled procedure expert when a safe and successful outcome cannot be ensured. Manual competence is also called technical or procedural } \\
\text { competence. }\end{array}$
\end{tabular}

Certification

An attestation of a hospitalist's basic competence to perform a procedure. ${ }^{107} \mathrm{~A}$ single certifying institution (typically a hospital) grants an intramural certification for performance of an ultrasound-guided procedure solely within that institution. In contrast, a national certifying institution (typically a specialty board or society) grants an extramural certification for performance of a procedure across multiple institutions. When unmodified, "certification" usually denotes extramural certification. ${ }^{108}$ An entrustment is a specific kind of certification that occurs in the context of a training program. It applies when a supervisor attests to the basic competence of a trainee to execute an unsupervised procedure. ${ }^{105}$ When formally acknowledged, an entrustment may lead to the awarding of a certificate. ${ }^{109}$

Credentialing The process outlined by an institution that a hospitalist follows to substantiate their own competence and worthiness of privilege. This is primarily done by accruing extramural certifications or other credentials that attest to successful completion of education, training, and experience. Intramural certifications of competence may be needed if a valid extramural certification is not available, ${ }^{108,110}$ as we herein suggest is currently the case for ultrasound-guided procedures.

Patient-based assessment $\quad$ Occurs during the performance of a procedure on an actual live patient in a real-world clinical setting

Performance review An analysis of procedures performed by a hospitalist during a specified time period. Rather than directly assessing a hospitalist's competence, a performance review indirectly assesses competence by providing proof of the ultrasound-guided procedures a hospitalist has performed, both successfully and unsuccessfully, during periods of having active privileges.

Privileging The process carried out by an institution, typically a hospital committee but not a hospitalist director, granting a privilege or allowance for a hospitalist to perform an ultrasound-guided procedure. This process usually includes verification of credentials and deliberation over past performance. Initial privilege is granted to a hospitalist who has not actively held that privilege, usually because he or she just completed residency or fellowship training, or because a previous privilege is no longer active. Ongoing privilege is granted to maintain an active privilege.

Simulator-based assessment Occurs during the performance of a procedure on a simulator (a task trainer or patient simulator) in a simulated clinical setting

Ultrasound guidance When a provider uses ultrasound to help with a bedside procedure. This can include any of the following: to identify the optimal needle insertion site (ie, site marking) to track the needle during insertion (ie, real-time guidance), and to evaluate for successful or adverse outcomes during or after a procedure. 


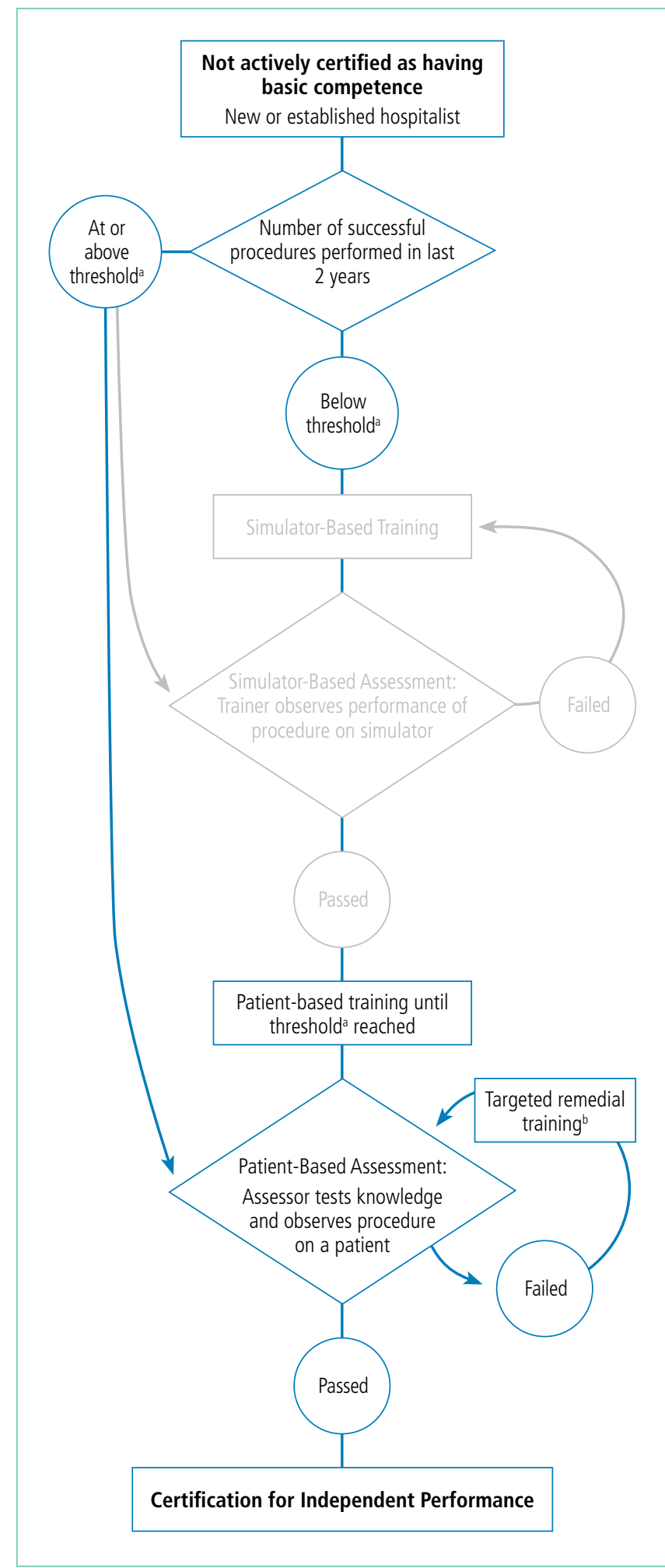

FIG 1. Assessment for intramural certification as part of initial credentialing for ultrasound-guided bedside procedures. When simulators are not available, ignore greyed-out components.

ainimum thresholds of experience should be determined by empirical methods, such as those based on cumulative sum analysis or local learning curves.

'Based on available resources and the hospitalist's performance on the patient-based assessment, the assessor should determine a remedial training program, which may include simulator-based training if available.

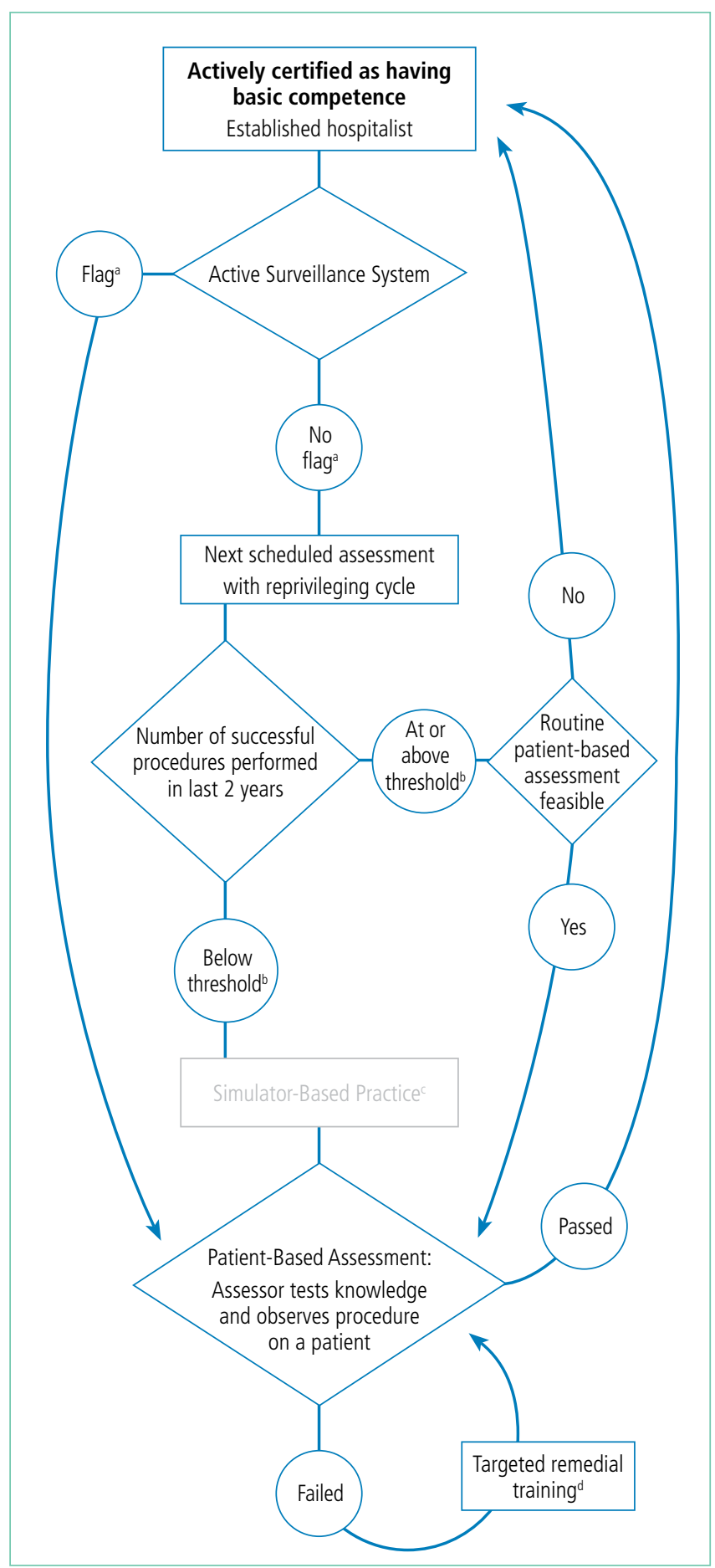

FIG 2. Assessment for intramural certification as part of ongoing credentialing for ultrasound-guided bedside procedures. When simulators are not available, ignore greyed-out components.

${ }^{a} \mathrm{~A}$ flag is a periprocedural safety event (both near misses and adverse events) caused by a provider error.

${ }^{b}$ Minimum thresholds of experience should be determined by empirical methods. 'Simulator-based practice can supplement patient-based experience.

'Based on available resources and the hospitalist's performance on the patient-based assessment, the assessor should determine a remedial training program, which may include simulator-based training if available. 
the certification pathways by using these survey results and codified individual aspects of these pathways into recommendations.

\section{Development of Position Statement}

Based on the Grading of Recommendation Assessment Development and Evaluation methodology, all final article selections were initially rated as either low-quality (observational studies) or unclassifiable (expert opinion). ${ }^{16}$ These initial ratings were downgraded further because of indirectness, because none of the articles involved the intervention of interest (a credentialing pathway) in a population of interest (hospitalists) measuring the outcomes of interest (patient-level outcomes). ${ }^{17}$ Given the universal low-quality evidence ratings, we altered the task force strategy of developing guidelines, which the other 4 working groups are writing, and instead developed a position statement by using consensus gathering in 3 steps.

First, the Credentialing Working Group drafted an initial position statement composed of recommendations for credentialing pathways and other general aspects of credentialing. All final article selections were incorporated as references in a draft of the position statement and compiled in a full-text compendium. Second, feedback was provided by the other 4 task force working groups, the task force peer reviewers, and the SHM Education Committee. Feedback was incorporated by the authors of this statement who were the Credentialing Working Group, the chairs of the other 4 working groups, and a guideline methodologist. Third, final suggestions from all members of the SHM POCUS Task Force and SHM Education Committee were incorporated before final approval by the SHM Board of Directors in September 2017.

\section{RESULTS}

A total of 1438 references were identified in the original search. Manual selection led to 101 articles, which were incorporated into the following 4 domains with 16 recommendations.

\section{General Credentialing Process}

\section{Basic Cognitive Competence Can Be Certified} with Written or Oral Examinations

The ABIM defines cognitive competence as having 3 abilities: "(1) to explain indications, contraindications, patient preparation methods, sterile techniques, pain management, proper techniques for handling specimens and fluids obtained, and test results; (2) to recognize and manage complications; and, (3) to clearly explain to a patient all facets of the procedure necessary to obtain informed consent. "1 These abilities can be assessed with written or oral examinations that may be integrated into simulation- or patient-based assessments. ${ }^{18-21}$

\section{Minimum Thresholds of Experience to Trigger the Timing of a Patient-Based Assessment Should Be Determined by Empirical Methods}

Learning curves are highly variable ${ }^{22-25}$ and even plateaus may not herald basic competence. ${ }^{26}$ Expert opinions ${ }^{27}$ can be used to establish minimum thresholds of experience, but such opinions may paradoxically exceed the current thresholds of experts' own hospitals. ${ }^{12}$ Thus, empirical methods, such as those based on cumulative sum analysis ${ }^{28-30}$ or local learning curves, ${ }^{31,32}$ are preferred. If such methods are not available, a recent survey of hospitalist experts may provide guidance. ${ }^{12}$ Regardless, once established, minimum thresholds are necessary but not sufficient to determine competency (see "Basic manual competence must be certified through patient-based assessments" section).

\section{Hospitalists Should Formally Log All of Their Attempted Procedures, Ideally in an Electronic Medical Record} Simple self-reported numbers of procedures performed often misrepresent actual experience ${ }^{33,34}$ and do not include periprocedural complications. ${ }^{35,36}$ Thus, hospitalists should report their experience with logs of all attempted procedures, both successful and unsuccessful. Such logs must include information about supervising providers (if applicable) and patient outcomes, including periprocedural adverse events, ${ }^{37}$ but they must also remain compliant with the Health Insurance Portability and Accountability Act.

\section{Health Information Technology Service Should Routinely Pull Collations of All Attempted Procedures from Comprehensive Electronic Medical Records}

Active surveillance may reduce complications by identifying hospitalists who may benefit from further training. ${ }^{38}$ In order to facilitate active surveillance systems, documentation (such as a procedure note) should be both integrated into an electronic medical record and protocol driven, ${ }^{39}$ including procedure technique, ultrasound findings, and any safety events (both near misses and adverse events).

\section{Basic Manual Competence Must Be Certified Through Patient-Based Assessments}

Multiple interacting factors, including environment, patients, baseline skills, training, experience, and skills decay, affect manual competence. Certifications that are based solely on reaching minimum thresholds of experience, even when accurate, are not valid reflections of manual competence, $15,40-43$ and neither are those based on self-perception. ${ }^{44}$ Patient-based assessments are, thus, necessary to ensure manual competence. ${ }^{45-48}$

\section{Certification Assessments of Manual Competence Should Combine 2 Types of Structured Instruments: Checklists and Overall Scores}

Assessments based on direct observation are more reliable when formally structured. ${ }^{49,50}$ Though checklists used in observed structured clinical examinations capture many important manual skills, ${ }^{51-56}$ they do not completely reflect a hospitalist's manual competence, ${ }^{57}$ situations may occur in which a hospitalist meets all the individual items on a checklist but cannot perform an entire procedure with basic competence. Therefore, checklists should be paired with overall scores. ${ }^{58-61}$ Both checklists and overall scores ought to be obtained from reliable and valid instruments. 
Certification Assessments Should Include Feedback

Assessments without feedback are missed learning opportunities. ${ }^{62}$ Both simulation- ${ }^{63}$ and patient-based assessments should provide feedback in real time to reinforce effective behaviors and remedy faulty ones.

\section{If Remedial Training is Needed, Simulator-Based Training Can Supplement but Not Replace Patient- Based Training}

Supervised simulator-based training allows hospitalists to master basic components of a procedure ${ }^{64}$ (including orientation to equipment, sequence of operations, dexterity, ultrasound anatomy, and real-time guidance technique) while improving both cognitive and manual skills. ${ }^{42,43,65-71}$ In addition to their role in basic training (which is outside the scope of this position statement), simulators can be useful for remedial training. To be sufficient for hospitalists who do not pass their patient-based assessments, however, remedial training that begins with simulation must also include patient-based training and assessment. ${ }^{72-75}$

\section{Initial Credentialing Process}

A Minimum Threshold of Experience Should Be Reached before Patient-Based Assessments are Conducted (Figure 1)

Recent experience, such as the number of successful procedures performed on a representative sample of patients $s^{61,76,77}$ in the last 2 years, should meet a minimum threshold (see "Minimum thresholds of experience to trigger the timing of a patient-based assessment should be determined by empirical methods" section) before a patient-based assessment for intramural certification occurs. ${ }^{31,78}$ Such procedures should be supervised unless performed with privileges, for example, at another hospital. After reaching both a minimum threshold of experience and passing an observed patient-based assessment, which includes assessments of both cognitive and manual skills, hospitalists can be considered intramurally certified for initial credentialing. The hospitalist may begin to independently perform ultrasound-guided procedures if all credentialing requirements are met and privileges are granted.

\section{Initial Certification Assessments Should Ideally Begin on Simulators}

Simulators allow the assurance of safe manual skills, including proper needle insertion techniques and disposal of sharp objects., ${ }^{3,79}$ If simulators are not available, however, then patient-based training and assessments can still be performed under direct observation. Safe performance of ultrasound-guided procedures during patient-based assessments (without preceding simulator-based assessments) is sufficient to certify manual competence.

\section{Ongoing Credentialing}

Certification to Perform Ultrasound-Guided Procedures Should Be Routinely Re-Evaluated During Ongoing Credentialing (Figure 2)
Ongoing certifications are needed because skills decay. ${ }^{80,81}$ They should be routine, perhaps coinciding with the usual reprivileging cycle (often biennually). When feasible, ${ }^{82}$ maintenance of manual competence is best ensured by directly observed patient-based assessments; when not feasible, performance reviews are acceptable.

\section{Observed Patient-Based Assessments Should Occur When a Periprocedural Safety Event Occurs that is Potentially Caused by "Provider Error"}

Safety events include both near misses and adverse events. Information about both is ideally "flagged" and "pushed" to hospitalist group leaders by active surveillance and reporting systems. Once reviewed, if a safety event is considered to potentially have been caused by provider error (including knowledge- and skill-based errors), ${ }^{83}$ then the provider who performed the procedure should undergo an observed patient-based assessment.

\section{Simulation-Based Practice Can Supplement Patient- Based Experience for Ongoing Credentialing}

When hospitalists do not achieve a minimum threshold of patient-based experience since the antecedent certification, simulation-based training can supplement their patient-based experience..$^{84}$ In these cases, however, an observed patient-based assessment must occur. Another consideration is whether or not the privilege should be relinquished because of an infrequent need.

\section{Credentialing Infrastructure \\ Hospitalists Themselves Should Not Bear the Financial Costs of Developing and Maintaining Training and Certification Programs for Ultrasound- Guided Procedures}

Equipment and personnel costs ${ }^{85,86}$ commonly impede ultrasound-guided procedure programs. ${ }^{4,87,88}$ Hospitalists whose job descriptions include the performance of ultrasound-guided procedures should not be expected to bear the costs of ultrasound machines, image archival software, equipment maintenance, and initial and ongoing training and certification.

\section{Assessors Should Be Unbiased Expert Providers Who Have Demonstrated Mastery in Performance of the Procedure Being Assessed and Regularly Perform It in a Similar Practice Environment}

Assessors should be expert providers who regularly perform the ultrasound-guided procedure in a similar practice environment. ${ }^{9,89-94}$ For example, providers who are not hospitalists but who are experts in an ultrasound-guided procedure and commonly perform it on the hospital wards would be acceptable assessors. However, a radiologist who only performs that procedure in a fully-staffed interventional radiology suite with fluoroscopy or computed tomography guidance would not be an acceptable assessor. More than 1 assessor may balance idiosyncratic assessments; ${ }^{95}$ but when assessments are 
well structured, additional assessors are generally not needed. ${ }^{18}$ Candidate assessors should be vetted by the hospitalist group leader and the hospital privileging committee.

\section{If Intramural Assessors Are Not Available, Extramural Assessors May Be Considered}

Intramural assessors are generally preferred because of familiarity with the local practice environment, including the available procedure kits and typical patient characteristics. Nevertheless, extramural assessors ${ }^{27,77,85,96}$ may theoretically provide even more valid assessments than intramural ones because extramural assessors are neither influenced by relationships with local hospitalists nor biased by local hospitalists' skills. ${ }^{97,98}$ Remote performance assessment through video recordings ${ }^{99}$ or live-video streaming is another option ${ }^{100}$ but is not sufficient unless a room camera is available to simultaneously view probe movement and the ultrasound screen. ${ }^{101}$ In addition, remote assessment does not allow the assessor to physically assume control of the procedure to either salvage it or perhaps, in some cases, prevent a complication.

\section{DISCUSSION}

There are no high-quality randomized trials in support of a single credentialing pathway over any other. ${ }^{94,102}$ The credentialing pathways at the center of this position statement are based on expert opinion. Our methods can be criticized straightaway, therefore, for reliance on the experience and expertise of our working group and task force. Any position statement written without high-quality supportive evidence would be appropriately subject to the same criticism. Without evidence in support of an overall pathway, we codified specific aspects of the pathways into 16 individual recommendations.

Patient-level outcomes do not back these recommendations. Consider, for example, our recommendation that certification assessments be made from structured instruments and not simply from an assessor's gestalt. Here, the basis is not improved patient-level outcomes from a trial (such as reduced complications or increased procedural success) but improved psychometric performance from reliability studies. The body of evidence for our recommendations is similarly indirect, mostly because the outcomes studied are more proximate and, thus, less meaningful than patient-level outcomes, which are the outcomes of greatest interest but are woefully understudied for clinical competence. ${ }^{17,97,103}$

The need for high-quality evidence is most pronounced in distinguishing how recommendations should be modified for various settings. Wide variations in resources and patient-mix will make some recommendations impracticable, meaning that they could not be carried out with available resources. For example, our recommendation that credentialing decisions should ultimately rely on certifications made by assessors during patient-based assessments may not be practicable at small, rural hospitals. Such hospitals may not have access to local assessors, and they may not admit enough patients who need the types of ultrasound-guided procedures for which hospitalists seek certification (especially given the need to coordinate the schedules of patients, procedure-performing hospitalists, and assessors). Collaborative efforts between hospitals for regional certification may be a potential solution to consider. But if recommendations are truly impracticable, the task force recognizes they may need to be modified. Given the low quality of evidence supporting our recommendations, such modifications would be readily defendable, especially if they emerged from collaborative discussions between privileging committees, hospitalist directors, and local experts.

One way for hospitals to implement our recommendations may be to follow a recommendation proposed by the authors of the original hospitalist core competencies over a decade ago: "The presence of a procedural skill in the Core Competencies does not necessarily indicate that every hospitalist will perform or be proficient in that procedure." ${ }^{104}$ In other words, bedside procedures may be delegated to some but not all hospitalists. Such "proceduralists" would have some proportion of their clinical responsibility dedicated to performing procedures. Delineation of this job description must be made locally because it balances 2 hospital-specific characteristics: patients' needs for procedures against the availability of providers with basic competence to perform them, which includes hospitalists but also emergency medicine physicians, specialists, and interventional radiologists. A salutary benefit for hospitals is that hospitalists who are not proceduralists would not need to undergo certification in basic competence for the bedside procedures they will not be performing.

Regardless of whether some or all hospitalists at a particular hospital are expected to perform bedside procedures, technology may help to improve the practicability of our recommendations. For example, simulators may evolve to replace actual patient-level experience in achieving minimum thresholds. Certification assessments of manual skills may even someday occur entirely on simulators. Real-time high-definition video streaming enhanced with multiple cameras may allow for remote assessments. Until such advances mature, high-quality patient-level data should be sought through additional research to refine our current recommendations.

We hope that these recommendations will improve how basic competence in ultrasound-guided bedside procedures is assessed. Our ultimate goal is to improve how hospitalists perform these procedures. Patient safety is, therefore, considered paramount to cost. Nevertheless, the hospital administrative leaders and privileging committee members on our Task Force concluded that many hospitals have been seeking guidance on credentialing for bedside procedures, and the likely difficulties of implementing our recommendations (including cost) would not be prohibitive at most hospitals, especially given recognition that these recommendations can be tailored to each setting.

\section{Acknowledgments}

Collaborators from SHM POCUS Task Force are Saaid Abdel-Ghani, Robert Arntfield, Jeffrey Bates, Anjali Bhagra, Michael Blaivas, Daniel Brotman, Caro- 
lina Candotti, Jagriti Chadha, Loretta Grikis, Richard Hoppmann, Susan Hunt, Venkat Kalidindi, Ketino Kobaidze, Joshua Lenchus, Benji Mathews, Paul Mayo, Satyen Nichani, Vicki Noble, Martin Perez, Nitin Puri, Aliaksei Pustavoitau, Kreegan Reierson, Sophia Rodgers, Gerard Salame, Daniel Schnobrich, Kirk Spencer, Vivek Tayal.

Disclosure: Brian P. Lucas received funding from the Department of Veterans Affairs, Veterans Health Administration, Office of Research and Development and Dartmouth SYNERGY, National Institutes of Health, and National Center for Translational Science (UL1TR001086). Nilam Soni received funding from the Department of Veterans Affairs, Quality Enhancement Research Initiative (QUERI) Partnered Evaluation Initiative (HX002263-01A1). The contents of this publication do not represent the views of the United States Department of Veterans Affairs or the United States Government.

The authors thank all the members of the Society of Hospital Medicine Pointof-care Ultrasound Task Force and the Education Committee members for their time and dedication to develop these guidelines.

CHAIRS: Nilam Soni, Ricardo Franco Sadud, Jeff Bates. WORKING GROUPS: Thoracentesis Working Group: Ria Dancel (chair), Daniel Schnobrich, Nitin Puri. Vascular Access Working Group: Ricardo Franco (chair), Benji Matthews, Saaid Abdel-Ghani, Sophia Rodgers, Martin Perez, Daniel Schnobrich. Paracentesis Working Group: Joel Cho (chair), Benji Matthews, Kreegan Reierson, Anjali Bhagra, Trevor P. Jensen. Lumbar puncture Working Group: Nilam Soni (chair), Ricardo Franco, Gerard Salame, Josh Lenchus, Venkat Kalidindi, Ketino Kobaidze. Credentialing Working Group: Brian P Lucas (chair), David Tierney, Trevor P. Jensen. PEER REVIEWERS: Robert Arntfield, Michael Blaivas, Richard Hoppmann, Paul Mayo, Vicki Noble, Aliaksei Pustavoitau, Kirk Spencer, Vivek Tayal. METHODOLOGIST: Mahmoud El Barbary. LIBRARIAN: Loretta Grikis. SOCIETY OF HOSPITAL MEDICINE EDUCATION COMMITTEE: Dan Brotman (past chair), Satyen Nichani (current chair), Susan Hunt. SOCIETY OF HOSPITAL MEDICINE STAFF: Nick Marzano.

\section{References}

1. American Board of Internal Medicine. Policies and procedures for certification. Philadelphia: American Board of Internal Medicine; 2006.

2. Nichani S, Fitterman N, Lukela M, Crocker J; Society of Hospital Medicine. The Core Competencies in Hospital Medicine 2017 Revision. Section 2: Procedures. J Hosp Med. 2017;12(4 Suppl 1):S44-S54

3. Lucas BP, Asbury JK, Franco-Sadud R. Training future hospitalists with simulators: a needed step toward accessible, expertly performed bedside procedures. J Hosp Med. 2009;4(7):395-396.

4. Schnobrich DJ, Gladding S, Olson APJ, Duran-Nelson A. Point-of-care ultrasound in internal medicine: a national survey of educational leadership. $J$ Grad Med Educ. 2013;5(3):498-502.

5. Brown GM, Otremba M, Devine LA, Gray C, Millington SJ, Ma IW. Defining competencies for ultrasound-guided bedside procedures: consensus opinions from Canadian physicians. J Ultrasound Med. 2016;35(1):129-141.

6. Vaisman A, Cram P. Procedural competence among faculty in academic health centers: challenges and future directions. Acad Med. 2017;92(1):31-34.

7. Kreisman RD. With ED ultrasound, credentialing is at issue. ED Legal Letter. 2010;21:102-103.

8. Goudie AM. Credentialing a new skill: what should the standard be for emergency department ultrasound in Australasia? Emerg Med Australas. 2010;22:263-264.

9. Maizel J, Guyomarc HL, Henon P, et al. Residents learning ultrasound-guided catheterization are not sufficiently skilled to use landmarks. Crit Care. 2014;18(1):R36. doi:10.1186/cc13741.

10. American College of Emergency Physicians. Ultrasound guidelines: emergency, point-of-care, and clinical ultrasound guidelines in medicine. Ann Emerg Med. 2017;69(5):e27-e54.

11. Amini R, Adhikari S, Fiorello A. Ultrasound competency assessment in emergency medicine residency programs. Acad Emerg Med. 2014;21(7):799-801.

12. Jensen T, Soni NJ, Tierney DM, Lucas BP. Hospital privileging practices for bedside procedures: a survey of hospitalist experts. J Hosp Med. 2017;12(10):836-839.

13. Chang W. Is hospitalist proficiency in bedside procedures in decline? The Hospitalist. 2012. http://www.the-hospitalist.org/hospitalist/article/125236/ patient-safety/hospitalist-proficiency-bedside-procedures-decline. Accessed September 30, 2017.

14. Barsuk JH, Feinglass J, Kozmic SE, Hohmann SF, Ganger D, Wayne DB. Spe- cialties Performing Paracentesis Procedures at University Hospitals: Implications for Training and Certification. J Hosp Med. 2014;9(3):162-168.

15. Barsuk JH, Cohen ER, Feinglass J, McGaghie WC, Wayne DB. Residents' Procedural Experience Does Not Ensure Competence: A Research Synthesis. J Grad Med Educ. 2017;9(2):201-208.

16. Balshem $H$, Helfand $M$, Schunemann HJ, et al. GRADE guidelines: 3 . Rating the quality of evidence. J Clin Epidemiol. 2011;64(4):401-406.

17. Guyatt GH, Oxman AD, Kunz R, et al. GRADE guidelines: 8 . Rating the quality of evidence-indirectness. J Clin Epidemiol. 2011;64(12):1303-1310.

18. Miller GE. The assessment of clinical skills/competence/performance. Acad Med. 1990;65(9 Suppl):S63-S67.

19. Grover S, Currier PF, Elinoff JM, Mouchantaf KJ, Katz JT, McMahon GT. Development of a test to evaluate residents knowledge of medical procedures. J Hosp Med. 2009:4(7):430-432.

20. Millington SJ, Wong RY, Kassen BO, Roberts JM, Ma IWY. Improving internal medicine residents' performance, knowledge, and confidence in central venous catheterization using simulators. J Hosp Med. 2009;4(7):410-416.

21. Lenchus JD, Carvalho CM, Ferreri K, et al. Filling the void: defining invasive bedside procedural competency for internal medicine residents. J Grad Med Educ. 2013;5(4):605-612.

22. Heegeman DJ, Kieke B Jr. Learning curves, credentialing, and the need for ultrasound fellowships. Acad Emerg Med. 2003;10:404-405.

23. Jang TB, Ruggeri W, Dyne P, Kaji AH. The learning curve of resident physicians using emergency ultrasonography for cholelithaisis and cholecystitis. Acad Emerg Med. 2010;17(11):1247-1252.

24. Akhtar MI, Hamid M. Ultrasound guided central venous access; a review of literature. Anaesth Pain Intensive Care. 2015;19:317-322.

25. Bahl A, Yunker A. Assessment of the numbers-based model for evaluation of resident competency in emergency ultrasound core applications. J Emerg Med Trauma Acute Care. 2015;2015(5). doi:10.5339/jemtac.2015.5

26. Cazes N, Desmots F, Geffroy Y, Renard A, Leyral J, Chaumoitre K. Emergency ultrasound: a prospective study on sufficient adequate training for military doctors. Diagn Interv Imaging. 2013;94(11):1109-1115.

27. Arntfield RT, Millington SJ, Ainsworth CD, et al. Canadian recommendations for critical care ultrasound training and competency for the Canadian critical care society. Can Respir J. 2014;21(16):341-345.

28. Bolsin S, Colson M. The use of the Cusum technique in the assessment of trainee competence in new procedures. Int J Qual Health Care. 2000;12(5):433-438.

29. de Oliveira Filho GR, Helayel PE, da Conceição DB, Garzel IS, Pavei P, Ceccon MS. Learning curves and mathematical models for interventional ultrasound basic skills. Anaesth Analg. 2008;106(2):568-573.

30. Starkie T, Drake EJ. Assessment of procedural skills training and performance in anesthesia using cumulative sum analysis (cusum). Can J Anaesth. 2013;60(12):1228-1239.

31. Tierney D. Competency cut-point identification derived from a mastery learning cohort approach: A hybrid model. Ultrasound Med Biol. 2015;41:S19.

32. Rankin JH, Elkhunovich MA, Rangarajan V, Chilstrom M, Mailhot T. Learning Curves for Ultrasound Assessment of Lumbar Puncture Insertion Sites: When is Competency Established? J Emerg Med. 2016;51(1):55-62.

33. Klasko SK, Cummings RV, Glazerman LR. Resident data collection: Do the numbers add up? Am J Obstet Gynecol. 1995;172(4 Pt 1):1312-1316.

34. Tierney D. Development \& analysis of a mobile POCUS tracking tool. Ultrasound Med Biol. 2015;41(suppl 4):S31.

35. Sethi MV, Zimmer J, Ure B, Lacher M. Prospective assessment of complications on a daily basis is essential to determine morbidity and mortality in routine pediatric surgery. J Pediatr Surg. 2016;51(4):630-633.

36. Fisher JC, Kuenzler KA, Tomita SS, Sinha P, Shah P, Ginsburg HB. Increased capture of pediatric surgical complications utilizing a novel case-log web application to enhance quality improvement. J Pediatr Surg. 2017;52(1): 166-171

37. Rethans JJ, Norcini JJ, Barón-Maldonado M, et al. The relationship between competence and performance: implications for assessing practice performance. Med Educ. 2002;36(10):901-909.

38. Duncan DR, Morgenthaler TI, Ryu JH, Daniels CE. Reducing iatrogenic risk in thoracentesis: establishing best practice via experiential training in a zero-risk environment. Chest. 2009;135(5):1315-1320.

39. Society of Critical Care Medicine Ultrasound Certification Task Force. Recommendations for achieving and maintaining competence and credentialing in critical care ultrasound with focused cardiac ultrasound and advanced critical care echocardiography. http://journals.Iww.com/ccmjournal/Documents/Critical\%20Care\%20Ultrasound.pdf Published 2013. Accessed February 2, 2017.

40. Carraccio C, Wolfsthal SD, Englander R, Ferentz K, Martin C. Shifting paradigms: from Flexner to competencies. Acad Med. 2002;77(5):361-367. 
41. Clark EG, Paparello JJ, Wayne DB, et al. Use of a national continuing medical education meeting to provide simulation-based training in temporary hemodialysis catheter insertion skills: a pre-test post-test study. Can J Kidney Health Dis. 2014;1:25-31.

42. Barsuk JH, Cohen ER, Caprio T, McGaghie WC, Simuni T, Wayne DB. Simulation-based education with mastery learning improves residents' lumbar puncture skills. Neurology. 2012;79(2):132-137.

43. Barsuk JH, McGaghie WC, Cohen ER, O'Leary KJ, Wayne DB. Simulation-based mastery learning reduces complications during central venous catheter insertion in a medical intensive care unit. Crit Care Med. 2009;37(10):2697-2701

44. Davis DA, Mazmanian PE, Fordis M, Van Harrison R, Thorpe KE, Perrier L. Accuracy of physician self-assessment compared with observed measures of competence: a systematic review. JAMA. 2006;296(9):1094-1102.

45. Shah J, Darzi A. Surgical skills assessment: an ongoing debate. BJU Int. 2001;88(7):655-660.

46. Lamperti M, Bodenham AR, Pittiruti M, et al. International evidence-based recommendations on ultrasound-guided vascular access. Intensive Care Med. 2012;38(7):1105-1117

47. Tolsgaard MG, Todsen T, Sorensen JL, et al. International multispecialty consensus on how to evaluate ultrasound competence: a Delphi consensus survey. PLOS One. 2013;8(2):e57687. doi:10.1371/journal.pone.0057687

48. Moureau N, Laperti M, Kelly LJ, et al. Evidence-based consensus on the in sertion of central venous access devices: definition of minimal requirements for training. Br J Anaesth. 2013;110(3):347-356.

49. Feldman LS, Hagarty S, Ghitulescu G, Stanbridge D, Fried GM. Relationship between objective assessment of technical skills and subjective in-training evaluations in surgical residents. J Am Coll Surg. 2004;198(1):105-110.

50. Baker S, Willey B, Mitchell C. The attempt to standardize technical and analytic competence in sonography education. J Diagn Med Sonogr. 2011;27(5):203-211.

51. Tolsgaard MG, Ringsted C, Dreisler E, et al. Reliable and valid assessment of ultrasound operator competence in obstetrics and gynecology. Ultrasound Obstet Gynecol. 2014;43(4):437-443.

52. Rice J, Crichlow A, Baker M, et al. An assessment tool for the placement of ultrasound-guided peripheral intravenous access. J Grad Med Educ. 2016;8(2):202-207.

53. Hartman N, Wittler M, Askew K, Hiestand B, Manthey D. Validation of a performance checklist for ultrasound-guided internal jubular central lines for use in procedural instruction and assessment. Postgrad Med J. 2017;93(1096): 67-70.

54. Primdahl SC, Todsen T, Clemmesen $\mathrm{L}$, et al. Rating scale for the assessment of competence in ultrasound-guided peripheral vascular access-a Delphi Consensus Study. J Vasc Access. 2016;17(5):440-445

55. Berg D, Berg K, Riesenberg LA, et al. The development of a validated checklist for thoracentesis: preliminary results. Am J Med Qual. 2013;28(3):220-226.

56. Berg K, Riesenberg LA, Berg D, et al. The development of a validated checklist for radial arterial line placement: preliminary results. Am J Med Qual. 2014;29(3):242-246

57. Walzak A, Bacchus M, Schaefer MP, et al. Diagnosing technical competence in six bedside procedures: comparing checklists and a global rating scale in the assessment of resident performance. Acad Med. 2015;90(8):1100-1108.

58. Riesenberg LA, Berg K, Berg D, et al. The development of a validated checklist for femoral venous catheterization: preliminary results. Am J Med Qual. 2014;29(5):445-450.

59. Riesenberg LA, Berg K, Berg D, et al. The development of a validated checklist for paracentesis: preliminary results. Am J Med Qual. 2013;28(3):227-231.

60. Huang GC, Newman LR, Schwartzstein RM, et al. Procedural competence in internal medicine residents: validity of a central venous catheter insertion assessment instrument. Acad Med. 2009;84(8):1127-1134

61. Salamonsen M, McGrath D, Steiler G, et al. A new instrument to assess physician skill at thoracic ultrasound, including pleural effusion markup. Chest 2013;144(3):930-934.

62. Boniface K, Yarris LM. Emergency ultrasound: Leveling the training and assessment landscape. Acad Emerg Med. 2014;21(7):803-805

63. Boyle E, O'Keeffe D, Naughton P, Hill A, McDonnell C, Moneley D. The importance of expert feedback during endovascular simulator training. J Vasc Surg. 2011;54(1):240-248.e1.

64. Langhan TS, Rigby IJ, Walker IW, Howes D, Donnon T, Lord JA. Simulation-based training in critical resuscitation procedures improves residents competence. CJEM. 2009;11(6):535-539.

65. Barsuk JH, McGaghie WC, Cohen ER, Balachandran JS, Wayne DB. Use of simulation-based mastery learning to improve the quality of centra venous catheter placement in a medical intensive care unit. $J$ Hosp Med. 2009;4(7):397-403

66. Lenchus JD. End of the "see one, do one, teach one" era: the next generation of invasive bedside procedural instruction. J Am Osteopath Assoc. 2010;110(6):340-346.

67. Barsuk JH, Cohen ER, Vozenilek JA, O'Connor LM, McGaghie WC, Wayne DB. Simulation-based education with mastery learning improves paracentesis skills. J Grad Med Educ. 2012;4(1):23-27.

68. McGaghie WC, Issenberg SB, Cohen ER, Barsuk JH, Wayne DB. Does simulation-based medical education with deliberate practice yield better results than traditional clinical education? A meta-analytic comparative review of the evidence. Acad Med. 2011;86(6):706-711.

69. Ross JG. Simulation and psychomotor skill acquisition: A review of the literature. Clin Simul Nurs. 2012;8(9):e429-e435.

70. Barsuk JH, Cohen ER, Potts S, et al. Dissemination of a simulation-based mastery learning intervention reduces central line-associated bloodstream infections. BMJ Qual Saf. 2014:23(9):749-756.

71. McSparron JI, Michaud GC, Gordan PL, et al. Simulation for skills-based education in pulmonary and critical care medicine. Ann Am Thorac Soc. 2015;12(4):579-586.

72. Kneebone RL, Scott W, Darzi A, Horrocks M. Simulation and clinical practice: strengthening the relationship. Med Educ. 2004;38(10):1095-1102.

73. Mema B, Harris I. The barriers and facilitators to transfer of ultrasound-guided central venous line skills from simulation to practice: exploring perceptions of learners and supervisors. Teach Learn Med. 2016;28(2):115-124.

74. Castanelli DJ. The rise of simulation in technical skills teaching and the implications for training novices in anaestheia. Anaesth Intensive Care. 2009;37(6):903-910.

75. McGaghie WC, Issenberg SB, Barsuk JH, Wayne DB. A critical review of simulation-based mastery learning with translational outcomes. Med Educ. 2014;48(4):375-385.

76. Langlois SLP. Focused ultrasound training for clinicians. Crit Care Med. 2007;35(5 suppl):S138-S143.

77. Price S, Via G, Sloth E, et al. Echocardiography practice, training and accreditation in the intesive care: document for the World Interactive Network Focused on Critical Ultrasound (WINFOCUS). Cardiovasc Ultrasound. 2008;6:49-83.

78. Blehar DJ, Barton B, Gaspari RJ. Learning curves in emergency ultrasound education. Acad Emerg Med. 2015;22(5):574-582.

79. Ault MJ, Rosen BT, Ault B. The use of tissue models for vascular access training. Phase I of the procedural patient safety initiative. J Gen Intern Med. 2006;21(5):514-517.

80. Barsuk JH, Cohen ER, McGaghie WC, Wayne DB. Long-term retention of central venous catheter insertion skills after simulation-based mastery learning. Acad Med. 2010;85(10 Suppl):S9-S12.

81. Sliman Sean, Amundson S, Shaw D, Phan JN, Waalen J, Kimura B. Recently-acquired cardiac ultrasound skills are rapidly lost when not used: implications for competency in physician imaging. J Amer Coll Cardiol. 2016;67(13S):1569.

82. Kessler CS, Leone KA. The current state of core competency assessment in emergency medicine and a future research agenda: recommendations of the working group on assessment of observable learner performance. Acad Emerg Med. 2012;19(12):1354-1359.

83. Chang A, Schyve PM, Croteau RJ, O'Leary DS, Loeb JM. The JCAHO patient safety event taxonomy: a standardized terminology and classification schema for near misses and adverse events. Int J Qual Health Care. 2005;17(2):95-105.

84. Sawyer $T$, White $M$, Zaveri $P$, et al. Learn, see, practice, prove, do, maintain: an evidence-based pedagogical framework for procedural skill training in medicine. Acad Med. 2015;90(8):1025-1033.

85. Das D, Kapoor M, Brown C, Ndubuisi A, Gupta S. Current status of emergency department attending physician ultrasound credentialing and quality assurance in the United States. Crit Ultrasound J. 2016;8(1):6-12.

86. Ndubuisi AK, Gupta S, Brown C, Das D. Current status and future issues in emergency department attending physician ultrasound credentialing. Ann Emerg Med. 2014;64(45):S27-S28.

87. Tandy Tk, Hoffenberg S. Emergency department ultrasound services by emergency physicians: model for gaining hospital approval. Ann Emerg Med. 1997;29(3):367-374

88. Lewiss RE, Saul T, Del Rios M. Acquiring credentials in bedside ultrasound: a cross-sectional survey. BMJ Open. 2013;3:e003502. doi:10.1136/bmjopen-2013-003502

89. Lanoix R. Credentialing issues in emergency ultrasonography. Emerg Med Clin North Am. 1997;15(4):913-920. 
90. Scalea T, Rodriquez A, Chiu WC, et al. Focused assessment with sonography for trauma (FAST): results from an international consensus conference. $J$ Trauma. 1999;46(3):466-472

91. Hertzberg BS, Kliewer MA, Bowie JD, et al. Physician training requirements in sonography: how many cases are needed for competence? AJR. 2000;174(5):1221-1227.

92. Blaivas M, Theodoro DL, Sierzenski P. Proliferation of ultrasound fellowships in emergency medicine: how do we ensure future experts are expertly trained? Acad Emerg Med. 2002;9(8):863-864

93. Bodenham AR. Editorial II: Ultrasound imaging by anaesthetists: training and accreditation issues. Br J Anaesth. 2006;96(4):414-417.

94. Williamson JP, Twaddell SH, Lee YCG, et al. Thoracic ultrasound recognition of competence: A position paper of the Thoracic Society of Australia and New Zealand. Respirology. 2017;22(2):405-408.

95. Harrison G. Summative clinical competency assessment: a survey of ultrasound practitioners' views. Ultrasound. 2015;23(1):11-17.

96. Evans LV, Morse JL, Hamann CJ, Osborne M, Lin Z, D'Onofrio G. The development of an independent rater system to assess residents' competence in invasive procedures. Acad Med. 2009;84(8):1135-1143.

97. Wass V, Van der Vleuten C, Shatzer J, Jones R. Assessment of clinical competence. Lancet. 2001;357(9260):945-949.

98. Arntfield RT. The utility of remote supervision with feedback as a method to deliver high-volume critical care ultrasound training. J Crit Care. 2015;30(2):441.e1-e6.

99. Akhtar S, Theodoro D, Gaspari R, et al. Resident training in emergency ultrasound: consensus recommendations from the 2008 Council of Emergency Residency Directors Conference. Acad Emerg Med. 2009;16:S32-S36.
100. Yu E. The assessment of technical skills in a cardiology training program: is the ITER sufficient? Can J Cardiol. 2000;16(4):457-462.

101. Todsen T, Tolsgaard MG, Olsen BH, et al. Reliable and valid assessment of point-of-care ultrasonography. Ann Surg. 2015;261(2):309-315

102. Stein JC, Nobay F. Emergency department ultrasound credentialing: a sample policy and procedure. J Emerg Med. 2009;37(2):153-159.

103. Chen FM. Burstin H, Huntington J. The importance of clinical outcomes in medical education research. Med Educ. 2005;39(4):350-351.

104. Dressler DD, Pistoria MJ, Budnitz TL, McKean SCW, Amin AN. Core competencies in hospital medicine: development and methodology. J Hosp Med. 2006; 1:48-56.

105. ten Cate $O$. Nuts and bolts of entrustable professional activities. J Grad Med Educ. 2013;5(1):157-158.

106. Castillo J, Caruana CJ, Wainwright D. The changing concept of competence and categorisation of learning outcomes in Europe: Implications for the design of higher education radiography curricula at the European level. Radiography. 2011;17(3):230-234.

107. Goldstein SR. Accreditation, certification: why all the confusion? Obstet Gynecol. 2007;110(6):1396-1398.

108. Moore CL. Credentialing and reimbursement in point-of-care ultrasound. Clin Pediatr Emerg Med. 2011;12(1):73-77.

109. ten Cate O, Scheele F. Competency-based postgraduate training: can we bridge the gap between theory and clinical practice? Acad Med. 2007;82(6):542-547.

110. Abuhamad AZ, Benacerraf BR, Woletz $P$, Burke BL. The accreditation of ultrasound practices: impact on compliance with minimum performance guidelines. J Ultrasound Med. 2004;23(8):1023-1029. 